\title{
Caucasian clover rhizobia are not a threat to nitrogen fixation by white clover
}

\author{
HEATHER N. PRYOR and W. L. LOWTHER \\ AgResearch, Invermay Agricultural Centre, PB 50034, Mosgiel \\ heather.pryor@agresearch.co.nz
}

\begin{abstract}
Caucasian clover has specific rhizobial requirements, and inoculation with a recommended strain is essential for nodulation and symbiotic $\mathrm{N}_{2}$ fixation. However, these rhizobia form nodules on white clover which do not fix nitrogen i.e. are ineffective. At the Nelson NZGA conference, Elliot and co-workers cautioned that caucasian clover rhizobia may over time reduce $\mathrm{N}_{2}$ fixation by white clover in New Zealand pastures. We have shown that high populations of caucasian clover rhizobia build up in the soil under swards of caucasian clover with numbers ranging from $10^{3}$ to $10^{6} / \mathrm{g}$ soil. A field trial was established on a site containing a naturalised population of rhizobia nodulating white clover $\left(10^{5} \mathrm{rhizobia} / \mathrm{g}\right.$ soil $)$. Treatments were imposed by mixing caucasian clover rhizobia into the soil, so that they made up $0,50 \%$ or $99 \%$ of the clover rhizobia population. The trial was then sown with uninoculated white clover seed. The planned levels of caucasian clover rhizobia were present after 1 month and there was only a small decline in numbers up to 22 months after sowing. White clover rhizobia increased over the first 14 months at least 10 -fold, to $\approx 10^{6} / \mathrm{g}$ soil even in the presence of caucasian clover rhizobia. There were no significant effects on white clover forage yield or on the calculated amount of $\mathrm{N}_{2}$ fixed, even when soil populations of caucasian clover rhizobia made up $99 \%$ of the population of clover rhizobia at sowing. This lack of effect could be explained by the small percentage (up to $5 \%$ ) of nodules on white clover formed by caucasian clover rhizobia. There is no doubt that high populations of caucasian clover rhizobia will develop in New Zealand soils with the increased use of caucasian clover and its associated rhizobia, but the presence of these rhizobia did not reduce symbiotic $\mathrm{N}_{2}$ fixation of white clover in this field experiment.
\end{abstract}

Keywords: caucasian clover, competition, nitrogen fixation, nodulation, rhizobia, Trifolium ambiguum, Trifolium repens, white clover

\section{Introduction}

Rhizobia that effectively nodulate caucasian clover (Trifolium ambiguum) are not naturally present in New Zealand soils and inoculation with a specific strain of rhizobia (Rhizobium leguminosarum bv. trifolii) is essential (Lowther et al. 1998). However, these rhizobia can form nodules on white clover (T. repens) that fail to fix $\mathrm{N}_{2}$. Elliot et al. (1998) drew attention to the possibility that the use of caucasian clover, and the associated build up of it's rhizobia in the soil, could lead to a reduction of symbiotic $\mathrm{N}_{2}$ fixation by white clover. This is supported by results from glasshouse trials (Pryor et al. 2004) where $\mathrm{N}_{2}$ fixation in white clover was significantly reduced when ineffective caucasian clover rhizobia made up a high proportion $(>92 \%)$ of rhizobia in the growth medium. These glasshouse results suggested that the use of the present strains of rhizobia for caucasian clover inoculants, and the possible build up of ineffective rhizobia in soil, may over time reduce $\mathrm{N}_{2}$ fixation and hence productivity of white clover based pastures. We concluded that a better understanding of the ecology of naturalised rhizobial populations in the field is required in order to predict the consequences of introducing rhizobia that are effective on caucasian clover into New Zealand soils.

To provide answers we surveyed populations of caucasian clover rhizobia that developed in soil under swards of caucasian clover in different environments and of different sward age. We also established a field trial and measured the effects of different populations of caucasian clover in the soil on nodulation, forage yield and $\mathrm{N}_{2}$ fixation of white clover under field conditions.

\section{Materials and methods}

\section{Survey of caucasian clover rhizobia under caucasian clover swards}

Soils under seven caucasian clover swards were sampled. Three of the swards had been oversown into mid-altitude ( $700-1100 \mathrm{~m}$ a.s.1.), undeveloped tussock grassland, 7 (Naseby) or 10 (Pisa Range and Crown Range) years previously and four were lowland pastures (Waitaki 1, 2, 3 and Invermay) sown 5 years before sampling. Populations of caucasian and white clover rhizobia were determined by the most probable number (MPN) method (Vincent 1970).

\section{Effect of caucasian clover rhizobia on white clover growth in the field}

\section{Site details and treatments}

The trial was established on a Wingatui silt loam on the Taieri Plain $\left(45^{\circ} 52.7 \mathrm{~S}, 170^{\circ} 20 \mathrm{E}\right)$ that had previously been cereal cropped for four years. Soil quick test values were pH 5.8, Olsen P $15 \mu \mathrm{g} / \mathrm{ml}$, sulphate-S $13 \mu \mathrm{g} / \mathrm{g}$, total nitrogen $(\mathrm{N}) 0.21 \%$ and with $10^{5}$ naturalised white clover 
rhizobia/g soil. The site was conventionally cultivated and plots of $1 \times 1 \mathrm{~m}$, with $1 \mathrm{~m}$ buffer between were laid out and a basal fertiliser dressing of $500 \mathrm{~kg} / \mathrm{ha} \mathrm{molybdic}$ superphosphate applied. Two rhizobia treatments were applied using peat inoculant $\left(\right.$ Nodulaid $\left.^{\circledR}\right)$ containing $10^{9}$ of caucasian clover rhizobia (ICC148)/g peat raked into the soil, using aseptic techniques, at rates calculated to deliver $10^{5}\left(50 \%\right.$ caucasian clover rhizobia) and $10^{7}(99 \%$ caucasian clover rhizobia) $/ \mathrm{g}$ soil to a depth of $7.5 \mathrm{~cm}$. The high rate needed $1 \mathrm{~kg}$ of peat inoculant per plot so horticultural peat was added to all other plots to equalise peat application. These two treatments and a control of no added caucasian clover rhizobia were sown in December 2001 with $5 \mathrm{~kg} / \mathrm{ha}$ white clover (cv. Huia) which was raked in. A treatment sown with ryegrass was included to give a measure of soil-N uptake. Treatments were randomised in 4 replicates blocks with buffer strips sown with browntop. Plots were maintained as pure legume or grass by hand weeding and herbicide application for the duration of the experiment. A basal dressing of $250 \mathrm{~kg} / \mathrm{ha}$ superphosphate and $100 \mathrm{~kg} / \mathrm{ha}$ potassium chloride was applied to all plots in September 2003.

\section{Forage yield and $\mathrm{N}$-uptake}

No herbage dry matter (DM) yields are presented for the first summer and autumn as growth was similar in legume and grass plots indicating the response to available soil-N. Legume and grass DM were determined over the 2002/2003 and 2003/2004 growing seasons and sub-samples were analysed for $\mathrm{N}$ content. Symbiotic $\mathrm{N}_{2}$ fixation in forage was calculated by subtracting grass $\mathrm{N}$-uptake from white clover $\mathrm{N}$-uptake. An analysis of variance (GenStat 2003) was carried out on herbage DM, forage $\% \mathrm{~N}$ and calculated symbiotic $\mathrm{N}_{2}$ fixation.

\section{Soil rhizobia populations}

Numbers of white and caucasian clover rhizobia in soil were determined by the MPN method 1, 14 and 22 months after sowing and significance determined by an analysis of variance.

\section{White clover nodule occupancy}

Six, 18 and 24 months after sowing, white clover roots were sampled and 24 nodules per plot randomly selected. These nodules were surface sterilised, squashed in sterile water and half the suspension added to a test tube containing a caucasian clover seedling and half to a test tube containing a white clover seedling growing on N-free nutrient agar (Vincent 1970). Control test tubes containing white and caucasian clovers inoculated with white (ICC101) or caucasian clover (ICC148) rhizobia were included. Seedlings growing on $\mathrm{N}$-free media depend solely on $\mathrm{N}_{2}$ fixation for growth, and after 6 weeks are large and green if fixation is effective and small and yellow if it is not. This visual technique allowed isolates from the original nodules to be classified as white clover rhizobia, caucasian clover rhizobia or dual (both white and caucasian rhizobia). An analysis of variance was carried out on the results.

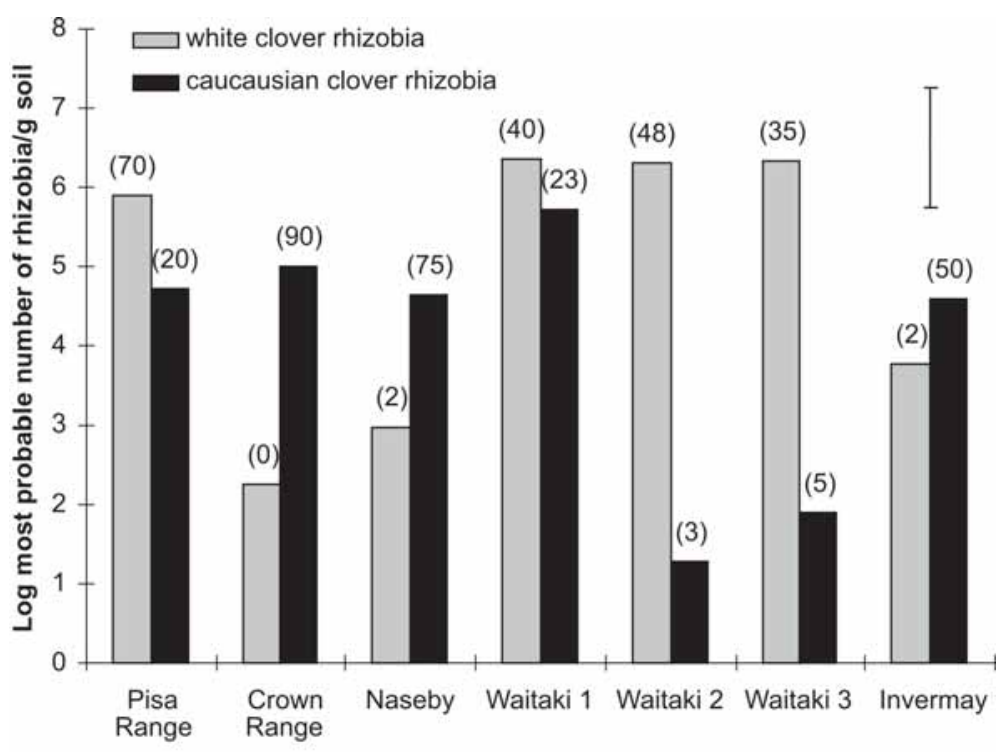

Tussock grasslands

Lowland pastures

\section{Results and discussion}

Populations of caucasian clover rhizobia in soil

Under caucasian clover swards

The results confirm Elliot et al. (1998) that caucasian clover rhizobia build up in New Zealand soils under caucasian clover swards. Numbers of caucasian clover rhizobia in the soil under established caucasian clover ranged from $\approx 10^{3}$ to $\approx$ $10^{6} / \mathrm{g}$ soil (Figure 1). Caucasian clover rhizobia numbers were higher $(\mathrm{P}<0.05)$ than the numbers of white clover rhizobia when there was more caucasian clover than white clover present 
in the tussock grassland swards. However, as pointed out by Pryor et al. (2004) it is difficult to determine accurately the number of white clover rhizobia in soil when they are less than the number of caucasian clover rhizobia. Caucasian clover rhizobia readily form ineffective nodules on white clover. These ineffective nodules can occupy all the nodule sites on seedlings in the MPN tubes, preventing the entry of white clover rhizobia, particularly at higher dilutions. The small, white/green (ineffective) nodules on white clover seedlings inoculated with suspensions at the high dilutions from Crown Range, Naseby and Invermay were typical of those formed by caucasian clover rhizobia. It is therefore possible that these soils may have had more white clover rhizobia present than suggested from values presented in Figure 1.

\section{Under white clover swards}

Results from the field trial indicate that caucasian clover rhizobia can be readily established in soil even in the absence of the host legume. One month after applying rhizobia peat inoculant, populations of caucasian clover rhizobia in the soil were $1.9 \times 10^{4}$ and $3.6 \times 10^{6} / \mathrm{g}$ soil. These were only slightly lower than the calculated application rates of $10^{5}$ and $10^{7} / \mathrm{g}$ soil, respectively (Figure $2 \mathrm{~A}$ ). The numbers of caucasian clover rhizobia in the soil remained high up to 22 months after application. The care taken to prevent spread of caucasian clover rhizobia was effective as there were less than $25 / \mathrm{g}$ soil in the control plots after 22 months.

The number of white clover rhizobia in the soil under white clover increased from one month after sowing to 14 months under the white clover host plants $(\mathrm{P}<0.001)$, and then remained constant (Figure 2B). It is of interest that the increase occurred in both presence and absence of caucasian clover rhizobia indicating little evidence of strain competition. As with the field survey, ineffective nodulation occurred on white clovers in MPN tubes inoculated by suspensions, at higher dilutions at the 1 month sampling of the plots with $10^{7}$ caucasian clover rhizobia added/g soil. This resulted in the estimated number of white clover rhizobia in this treatment being

A.
Figure 2 Number (log/g soil) of caucasian clover (A) and white clover (B) rhizobia in field plot soils inoculated so that caucasian clover rhizobia made up $0 \%, 50 \%$ or $99 \%$ of the clover rhizobia population. Bars denote LSD $(\mathrm{P}<0.05)$.

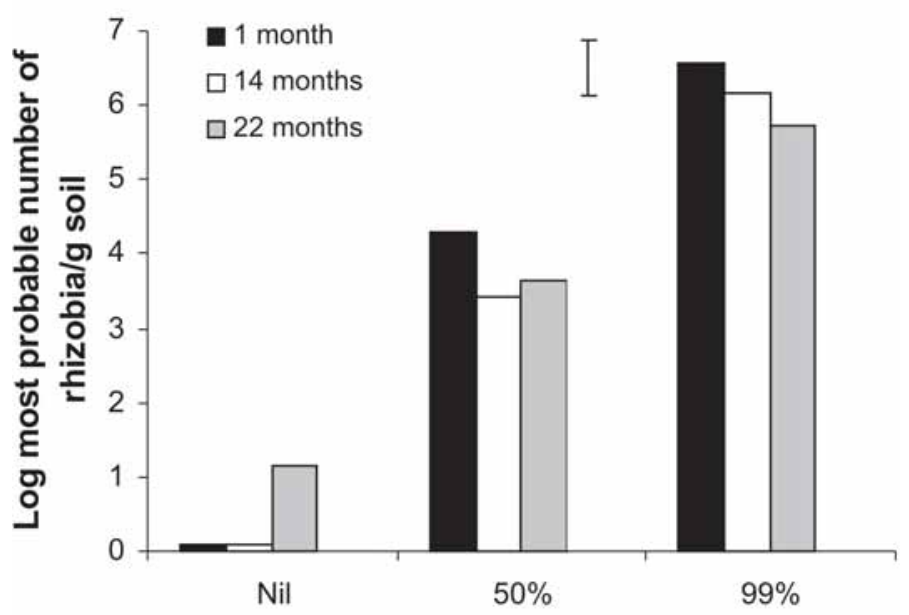

Initial \% caucasian clover rhizobia in the soil

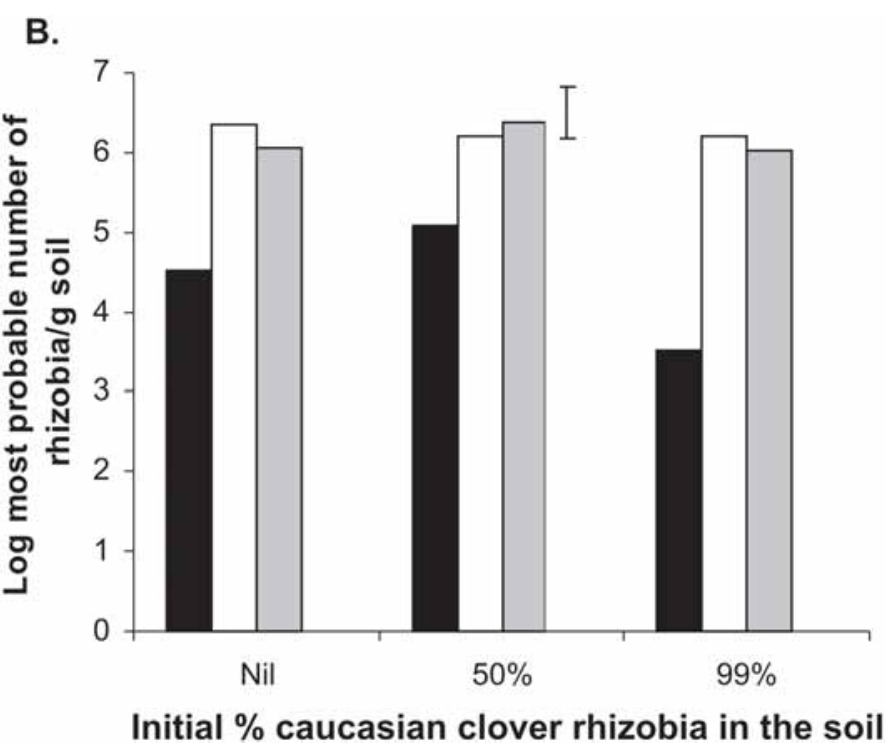

lower than in the control treatment. However, as the number of rhizobia in the three treatments was similar at 14 and 22 months it appears that the increase in the soil populations of white clover rhizobia to levels similar to caucasian clover rhizobia overcame the ineffective nodulation in the $99 \%$ treatment.

\section{White clover nodule occupancy}

No nodules on white clover roots were occupied solely by caucasian clover rhizobia in the $50 \%$ caucasian 
Figure 3 Percent of nodules on white clover occupied by caucasian or white clover rhizobia in soils inoculated so that caucasian clover rhizobia made up $50 \%$ or $99 \%$ of the population.

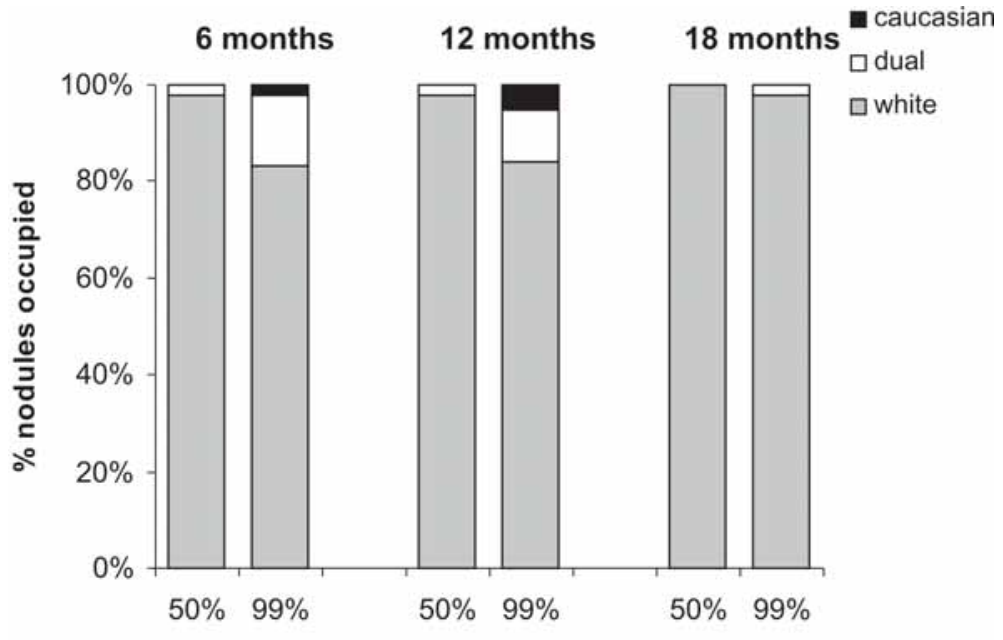

rhizobia from white clover are more competitive at forming nodules on white clover than the ineffective rhizobia from caucasian clover under field conditions. Reasons for the marked difference in competitiveness of caucasian clover rhizobia between a previous glasshouse experiment (Pryor et al. 2004) and this field trial are unclear. However, environmental conditions (Thies et al. 1992) and different growth media (Singer et al. 1964) have been shown to determine which components of the rhizobial population dominate in forming nodules.

\section{$\%$ caucasian rhizobia in the soil}

rhizobia treatment at any sampling or in the $99 \%$ caucasian clover treatment at 18 months (Figure 3). Some ( 2 and $5 \%$ ) nodules were occupied solely by caucasian clover rhizobia in the $99 \%$ caucasian clover rhizobia treatments at the first two samplings. There was also a significant difference $(\mathrm{P}<0.01)$ between these two treatments in the number of dual occupancy nodules (i.e. occupied by both white and caucasian rhizobia) which increased from $2 \%$ to $13 \%$ as caucasian clover rhizobia increased from $50 \%$ to $99 \%$. Although dual occupancy has been reported in the literature (Denton et al. 2003), its significance on symbiotic $\mathrm{N}_{2}$ fixation is unclear.

These results clearly indicate that the effective

\section{Forage yield and $\mathrm{N}$-uptake}

The presence of $50 \%$ or $99 \%$ caucasian clover rhizobia in the soil had no significant effect $(\mathrm{P}>0.05)$ on white clover forage DM (Figure $4 \mathrm{~A}$ ), $\% \mathrm{~N}$ in the forage or calculated symbiotic $\mathrm{N}_{2}$ fixation (Figure 4B) in either year. This result conflicts with the glasshouse results of Pryor et al. (2004) who found that the presence of $>92 \%$ of caucasian clover rhizobia in the population significantly reduced $\mathrm{N}_{2}$ fixation in white clover. The lack of effect in the field trial can be explained by the small percentage of nodules formed on white clover by caucasian clover rhizobia. It is likely that the white clover plants would have compensated for the slightly lower percentage of effective nodules by increasing the

Figure 4 White clover DM (A) and calculated amount of $\mathrm{N}$ derived from symbiotic fixation (B), over the 2002/ 03 and 2003/04 growing seasons, in soils inoculated so that caucasian clover rhizobia made up 0 , $50 \%$ or $99 \%$ of the population. Bars denote LSD $(P<0.05)$.

A.

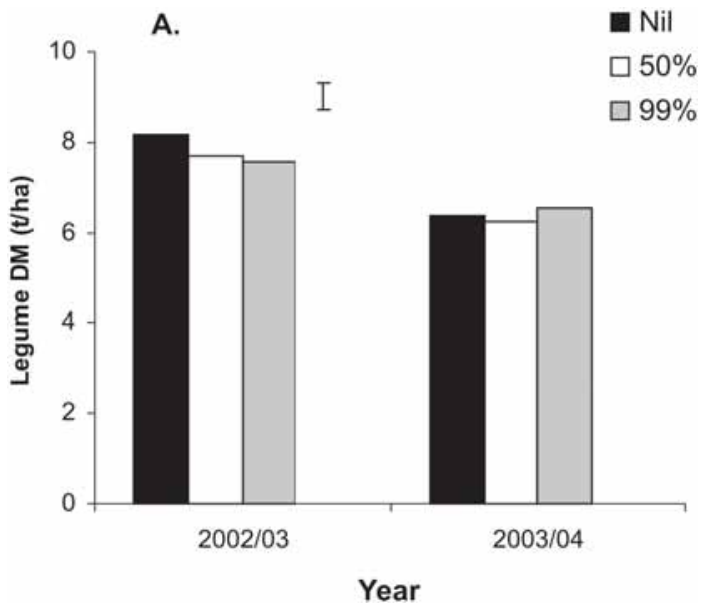

B.

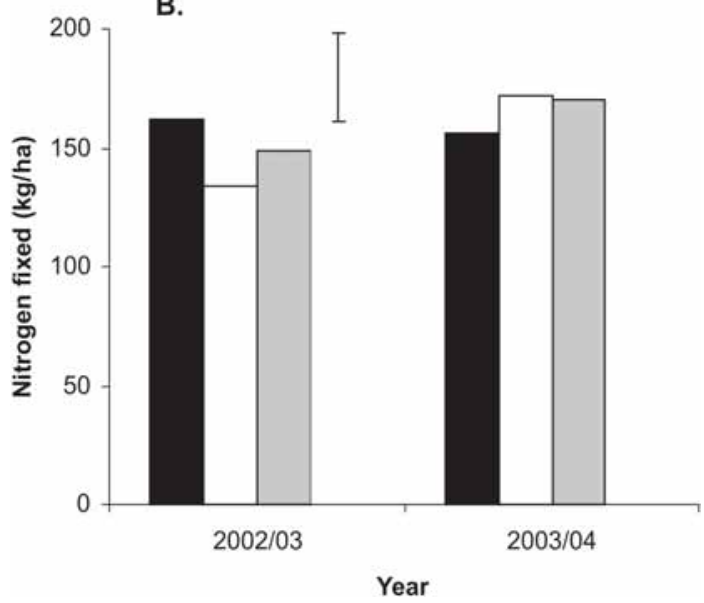


size of individual nodules (Singleton \& Stockinger 1983). This compensatory mechanism tends to keep the amount of effective nodule tissue constant and deleterious effects on $\mathrm{N}_{2}$ fixation only occur when the ineffective nodulation is great enough to reduce nodule mass.

The proportions of caucasian clover rhizobia in the soil generated in the field experiment are as high as any detected under established swards of caucasian clover. The results therefore suggest that caucasian clover rhizobia are unlikely to interfere with symbiotic $\mathrm{N}_{2}$ fixation of established white clover. However, the present results do not discount the possibility of high populations of caucasian clover rhizobia affecting white clover seedling growth in low fertility situations. White clover seedlings could be particularly vulnerable to the combined effects of reduced $\mathrm{N}_{2}$ fixation caused by ineffective nodulation (Schomberg \& Weaver 1990) and the metabolic burden of forming parasitic nodules. This aspect could not be investigated in the present experiment because there was sufficient available soil-N for seedling growth.

\section{Conclusions}

1. Rhizobia forming effective nodules on caucasian clover are not naturally present in New Zealand soils but high populations have built up with the use of inoculated caucasian clover.

2. Caucasian clover rhizobia can form nodules on white clover but do not fix nitrogen.

3. In the field, caucasian clover rhizobia are not as competitive at forming nodules on white clover as the existing soil rhizobia population.

4. Introduction of caucasian clover rhizobia does not appear to reduce symbiotic- $\mathrm{N}_{2}$ fixation in white clover under field conditions.

\section{ACKNOWLEDGEMENTS}

We wish to thank Mr Clive Wallis of Wallis's Nursery for use of land. This work was funded by the New Zealand Foundation for Research, Science and Technology.

\section{REFERENCES}

Denton, M.D.; Reeves, W.G.; Howieson, J.G.; Coventry, D.R. 2003. Competitive abilities of common field isolates and a commercial strain of Rhizobium leguminosarum bv. trifolii for clover nodule occupancy. Soil Biology and Biochemistry 35: 1039-1048.

Elliot, R.M.; McIntyre, H.J.; Challis, B.C.; Pryor, H.N.; Lowther, W.L.; Ronson, C.W. 1998. Rhizobium issues affecting the contribution of caucasian clover to New Zealand pastoral agriculture. Proceedings of the New Zealand Grassland Association 60: 207-211.

GenStat 2003. GenStat for Windows. Seventh Edition. Version 7.1.0.201. VSN International Ltd, Hemel Hempstead.

Lowther, W.L.; Pryor, H., N.; Trainor, K.D. 1998. Strategies to maximise establishment and production of oversown caucasian clover. Proceedings of the New Zealand Grassland Association 60: 111-114.

Pryor, H.N.; Elliot, R.M.; Lowther, W.L.; Ronson, C.W. 2004. Effect of rhizobia from caucasian clover (Trifolium ambiguum) on nodulation and nitrogen fixation of white clover (Trifolium repens). New Zealand Journal of Agricultural Research 47: 75-83.

Schomberg, H.H.; Weaver, R.W. 1990. Early growth and dinitrogen fixation by arrowleaf clover in response to starter nitrogen. Agronomy Journal 82: 946-951.

Singer, M.; Holding, A.J.; King, J. 1964. The response of Trifolium repens to inocula containing varying proportions of effective and ineffective rhizobia. 8 th International Congress of Soil Science: 1021-1025.

Singleton, P.W.; Stockinger, K.R. 1983. Compensation against ineffective nodulation in soybean. Crop Science 23: 69-72.

Thies, J.E.; Bohlool, B.B.; Singleton, P.W. 1992. Environmental effects on competition for nodule occupancy between introduced and indigenous rhizobia and among introduced strains. Canadian Journal of Microbiology 38: 493-500.

Vincent, J.M. 1970. A Manual for the Practical Study of the Root-Nodule Bacteria. Blackwell Scientific Publications, Oxford and Edinburgh. 164 pp. 
